The final published version of this article can be found at http://dx.doi.org/10.1055/s-0030-1260570. 


\section{Alternative Approaches to Enolate Chemistry}

Tom D. Sheppard.

Department of Chemistry, University College London, Christopher Ingold Laboratories, 20 Gordon St, London, WC1H 0AJ, UK.

Fax: +44 (0) 2076797463

E-mail: tom.sheppard@ucl.ac.uk

Received: The date will be inserted once the manuscript is accepted.

Abstract: This article highlights recently developed methods for the in-situ generation of enolates from non-carbonyl precursors. Suitable enolate precursors include allylic alcohols, vinyl borates and alkynes.

Key words: aldol reaction, alkynes, allylic alcohols, catalysis, enolates.

Enolates play a central role in synthetic chemistry as important intermediates for carbon-carbon and carbonheteroatom bond formation. They are usually prepared from the parent carbonyl compound (Scheme 1) by deprotonation with a strong base such as LDA (a), or by reaction with a mild base in the presence of a Lewis acid (b). However, neither of these methods are compatible with the presence of the intended electrophile, especially if this electrophile also contains a carbonyl group. Typically this means that the enolate formation must be carried out separately, before addition of the electrophile in a subsequent step. Enolate chemistry can also be effectively accessed via conjugate addition of nucleophiles to $\alpha, \beta$-unsaturated carbonyl compounds (c) ${ }^{1}$ and via the formation of enamines (d), ${ }^{2}$ and many useful asymmetric reactions have been developed using these approaches.

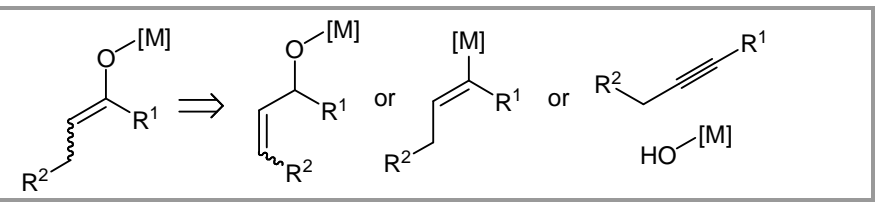

Scheme 2 Alternative enolate precursors

The generation of enolates via isomerisation of allylic alcohols or their corresponding alkoxides is a very atom economical and attractive method (Scheme 3).

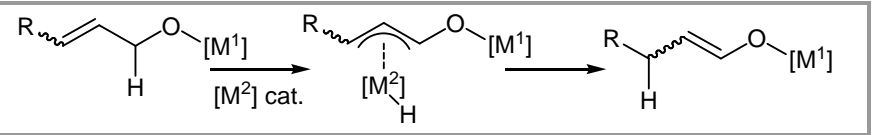

Scheme 3 General approach to enolates from allylic alkoxides

This concept was first realized in the early 1990s when it was found that rhodium ${ }^{3}$ and nickel ${ }^{4}$ catalysts could readily mediate the isomerisation of allylic alkoxides to give the corresponding enolates. The enolates could then be trapped in subsequent reactions with alkylating agents or aldehydes (Scheme $4, \mathbf{1}$ ).

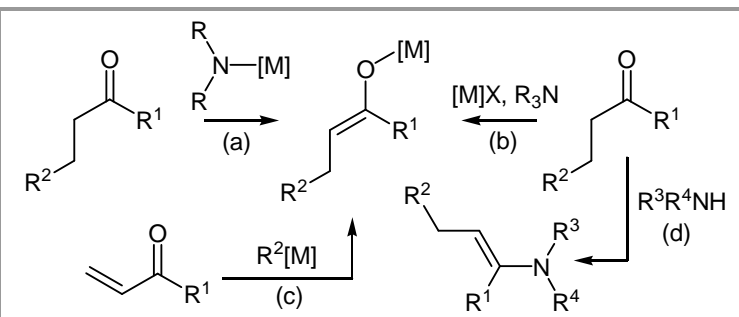

Scheme 1 Enolate formation from carbonyl precursors.

An unusual alternative strategy, however, is to generate an enolate directly from a non-carbonyl precursor. Until relatively recently, this approach has been largely unexplored, despite its many possible advantages. Most significantly, the chemoselective generation of an enolate, can potentially be achieved in the presence of the electrophile, even if that electrophile is itself an enolisable carbonyl compound. Plausible enolate precursors (Scheme 2) include allylic alcohols (via isomerisation), vinyl organometallics (via oxidation) and alkynes (via addition of a metal hydroxide).

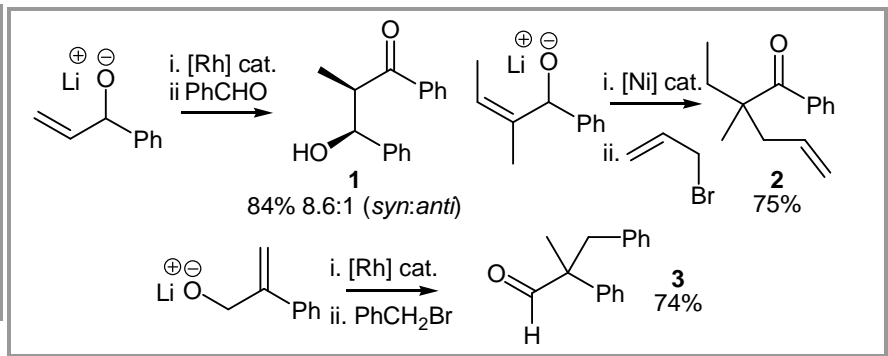

Scheme 4 Generation of enolates from allylic alkoxides

The nickel catalysts were found to be more active, and could be used to access highly substituted enolates which, after alklylation, led to the formation of all carbon quaternary centres (2). This approach is also particularly valuable for accessing aldehyde enolates which are otherwise difficult to generate (3). Whilst these methods are effective, the isomerisation conditions are somewhat harsh (high temperatures and strong bases) and they are incompatible with the presence of electrophiles such as aldehydes, which must be added to the reaction mixture after the isomerisation is complete. More recently, attention has been focused on the direct isomerisation of allylic alcohols themselves. This can lead to the catalytic 
generation of an enol or a metal enolate depending on the reaction conditions. This intermediate can be trapped with an electrophile already present in the reaction mixture, leading to a variety of useful products (Scheme 5). A wide range of metal catalysts have been employed including systems based on iron (a), ${ }^{5,6}$ nickel (b), ${ }^{6,7}$ rhodium $(\mathrm{c})^{8,9}$ and ruthenium $(\mathrm{d}){ }^{8,}{ }^{10}$ With iron catalysts the enolate formation is not completely regioselective (a). However, some of the $\mathrm{Ni}^{7 \mathrm{a}}$ and $\mathrm{Ru}^{10}$ systems are particularly effective, giving good yields of the resulting aldol products with relatively low catalyst loadings. The isomerisation reactions can be carried out in the presence of the desired electrophile in most cases, and successful aldol reactions with enolisable aldehydes have been achieved. Notably, the enolates can also be trapped with activated imines in Mannich reactions. $5 \mathrm{~b}, 8 \mathrm{~b}, 9$

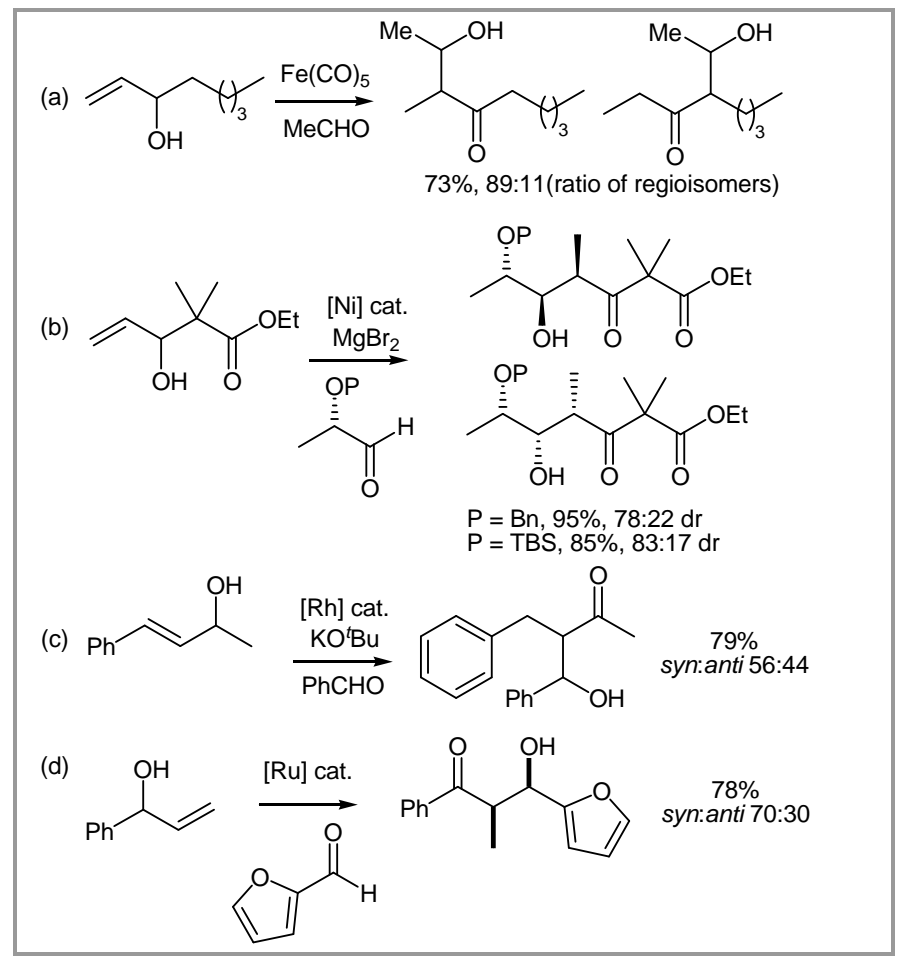

Scheme 5 Generation of enolates from allylic alcohols

The generation of enolates via the oxidation of vinylmetal species such as boranes/borates or silanes is an interesting strategy that has not been widely explored. $^{11,12}$ A two step sequence can be envisaged, via hydrometallation of an alkyne, followed by oxidation of the carbon-'metal' bond to yield the enolate (Scheme 6).

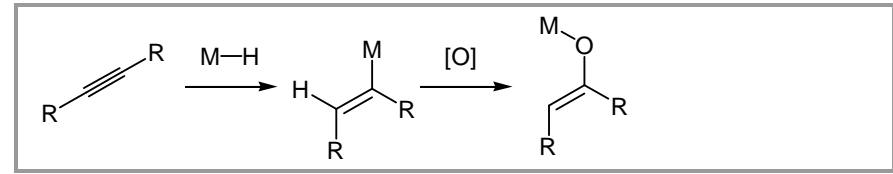

Scheme 6 Enolate formation via oxidation of a vinylmetal species.

Vinylborates or vinylboranes can be oxidized under anhydrous conditions using an amine oxide, generating an enolate which can readily undergo aldol reaction via a closed transition state. ${ }^{11,12}$ Chiral derivatives such as $\mathbf{4}$ have even been prepared and the resulting syn aldol products 5 were obtained with moderate enantiomeric excess (Scheme 7). ${ }^{11}$

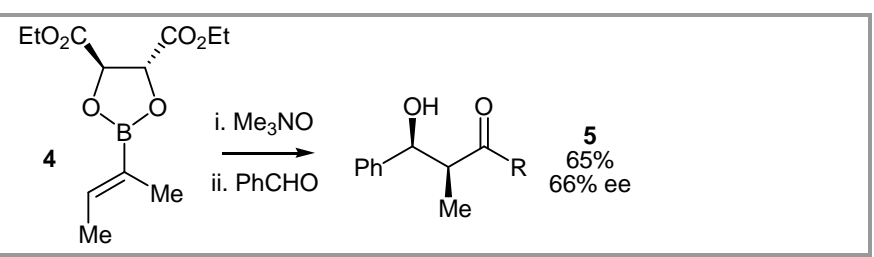

Scheme 7 Aldol reaction using a vinylborate enolate precursor

A particularly intriguing method for enolate synthesis is the addition of a metal hydroxyl species to an alkyne (Scheme 8). This can potentially provide access to geometrically controlled enolates under very mild conditions. Given the widespread availability of alkynes, this approach could be particularly powerful.

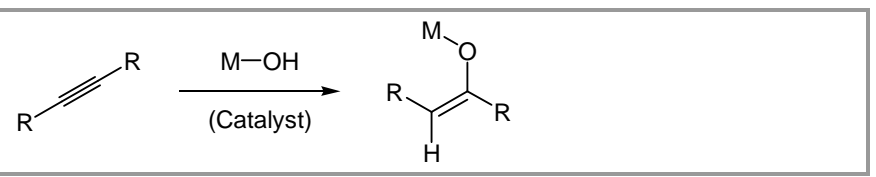

Scheme 8 Enolate formation from an alkyne

Perhaps unsurprisingly, research in this area has focused on the use of readily accessible (and stable) metalhydroxy species based on boron and silicon. The first report of such an approach to enolates involved the mercury-mediated addition of diphenylborinic acid to ethoxyacetylene (Scheme 9). ${ }^{13}$ This provides access to the boron enolate of ethyl acetate, which can readily be trapped with an aldehyde present in the reaction mixture, to give aldol products such as $\mathbf{6}$. The method was applied to a synthesis of 2-deoxy-D-ribose, via stereoselective aldol reaction with readily enolisable glyceraldehyde acetonide to give 7, demonstrating the useful chemoselectivity of this reaction.

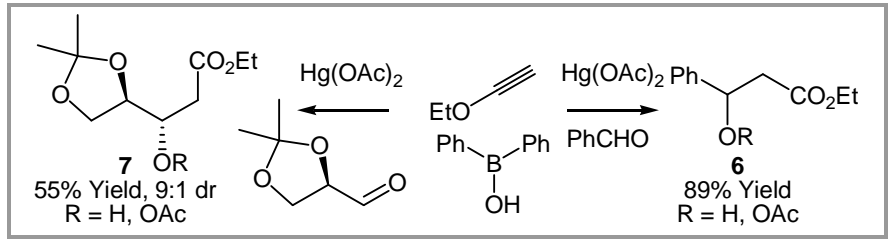

Scheme $9 \mathrm{Hg}$-mediated enolate formation using a borinic acid

Unfortunately, the reaction requires stoichiometric quantities of $\mathrm{Hg}(\mathrm{OAc})_{2}$ to proceed effectively and the aldol products were also obtained as a mixture of the free alcohol and the corresponding acetate. Very recently, a method for the catalytic addition of silanols to acetylinic oxazolidinones has been reported (Scheme 10). ${ }^{14}$ In this case, a Lewis acidic metal salt such as $\mathrm{Sc}(\mathrm{OTf})_{3}$ or $\mathrm{Zn}(\mathrm{OTf})_{2}$ was used to mediate the addition of the silanol across the alkyne. The Lewis acid also serves to activate 
the aldehyde towards reaction with the silyl enol ether intermediate.

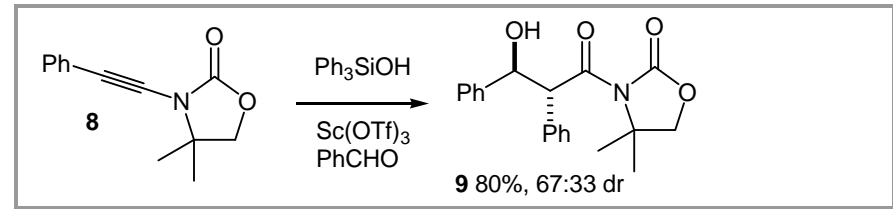

Scheme 10 Aldol reaction using an alkynyl oxazolidinone enolate precursor

The reaction presumably proceeds via co-ordination of the silanol to the Lewis acid, and protonation of the electron-rich alkyne (Scheme 11). Subsequent trapping with the silanol leads to the 'enolate' intermediate. The authors proposed that geometrical control over the formation of the enolate $\mathbf{1 1}$ is obtained via addition of the silanol to the least hindered face of ketiminium ion $\mathbf{1 0}$.

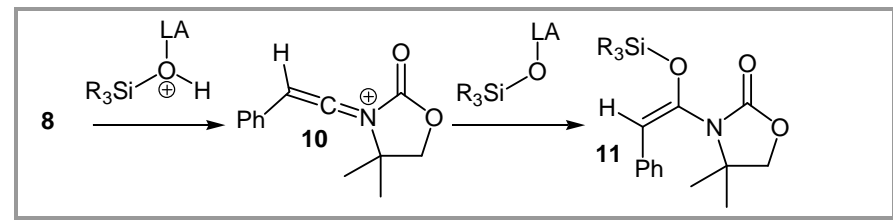

Scheme 11 Proposed enolate generation mechanism

In our own work, we have employed a gold catalyst to mediate the addition of a boronic acid across an alkyne to give a boron enolate (Scheme 12). ${ }^{15}$ This concept was exemplified by the intramolecular cyclisation of a range of ortho-alkynylbenzene boronic acids 12, which proceeded exclusively via 6-endo-dig cyclisation to give the unusual boron enolates 13.

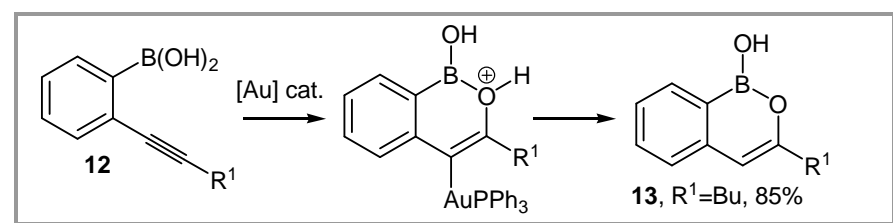

Scheme 12 Gold-catalyzed enolate formation from an alkyne

These compounds show unexpected stability, possibly due to aromatic stabilization in the newly formed ring, although theoretical studies on related systems have cast doubt on the degree of aromatic character in such ring systems. ${ }^{16}$ Enolates such as $\mathbf{1 3}\left(\mathrm{R}^{1}=\mathrm{Bu}\right)$ can readily be isolated via chromatography, but nevertheless show typical enolate reactivity in aldol reactions. The enolate generation conditions are compatible with the presence of even very reactive aldehydes such as acetaldehyde, and one-pot enolate formation/aldol reactions proceed very efficiently at room temperature in the presence of only 1$2 \mathrm{~mol} \%$ of the gold catalyst (Scheme 13).

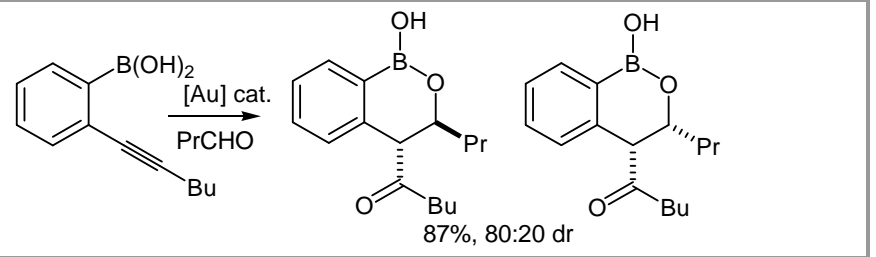

Scheme 13 One-pot gold-catalyzed enolate formation/aldol reaction.

In nearly all reactions the trans-isomer was the major product, although the stereoselectivity was generally moderate. This is perhaps unsurprising as the enolates $\mathbf{1 3}$ are very flat systems which are unlikely to react via chair-like transition states. The aldol reaction could proceed via either a closed (14) or open (15) transition state. The closed transition state is likely to resemble a cycloaddition reaction, with the two transition states leading to the syn (14a) and anti (14b) products only differing in the placement of the aldehyde substituent - it is either placed over $\mathrm{R}^{1}$ or over the aromatic ring. The orientation of the aldehyde substituent is reversed in an open transition state, with the syn product being obtained when it is placed over the aromatic ring (15b) and the anti product being obtained when it is placed over the $\mathrm{R}^{1}$ group (15a). In all of the examples studied, the stereoselectivity appears to be largely determined by the nature of the group at $\mathrm{R}^{1}$. Increasing the size of the group at $\mathrm{R}^{1}$ tended to result in lower selectivity, perhaps suggesting that an open transition state may be operative in these reactions.

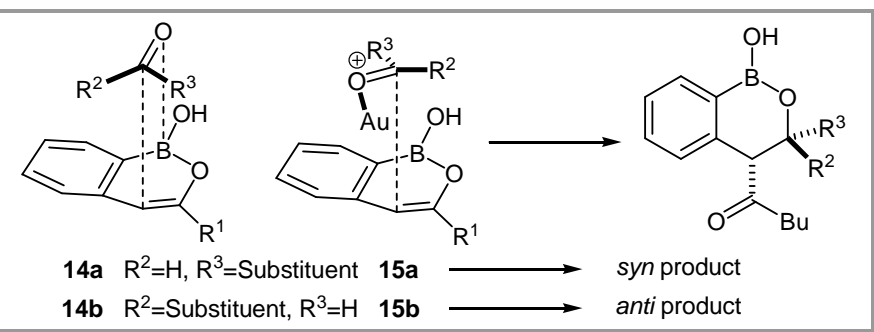

Figure 1 Possible 'closed' and 'open' aldol transition states.

The aldol products themselves (16) are not stable enough to be isolated in some cases, being prone to retro-aldol reaction during purification. Procedures were therefore developed for the direct functionalisation of these products via reaction of the boron moiety (Scheme 14). Oxidation of the boronic acid to the corresponding phenol (e.g. 17) proceeded very efficiently in the presence of mcpba, and a range of products were isolated in good to excellent yield as the hydroxyphenol or the corresponding diacetate. Similarly, Suzuki cross-coupling of the boronic acid with iodoarenes provided access to biaryl systems (18) in good yield. Interestingly, intramolecular Chan-Lam coupling ${ }^{17}$ of these systems to give dihydrobenzofurans (19) was found to be very facile with only a catalytic quantity of $\mathrm{Cu}(\mathrm{OAc})_{2}$ in $\mathrm{MeOH}$ being required. 


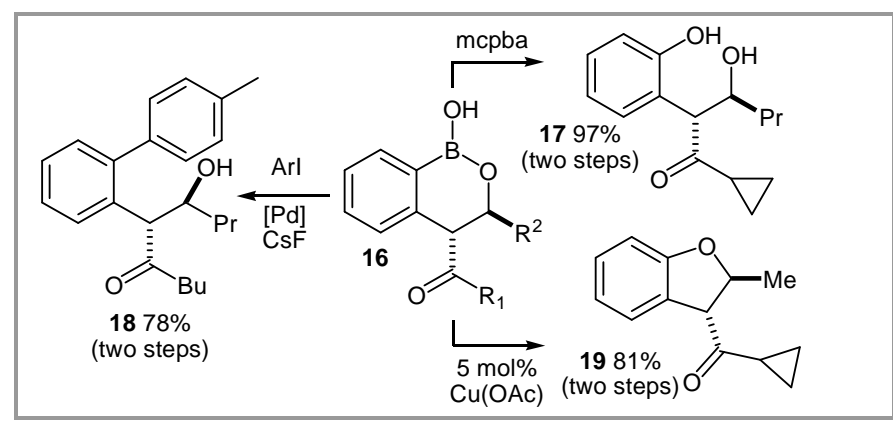

Scheme 14 Further transformations of the aldol products

Chan-Lam couplings of aliphatic alcohols are fairly rare, and in nearly all couplings of this type a stoichiometric quantity of copper salt is needed. ${ }^{17,}{ }^{18}$ In contrast, 16 undergoes rapid intramolecular coupling to give access to the 2,3-disubstituted dihydrobenzofuran systems in good yield. This ring system is of interest in medicinal chemistry, as a number of natural products containing this moiety have been reported to have potentially useful biological properties. ${ }^{19}$ Our two step approach from readily available ortho-alkynylbenzene boronic acids provides a useful new method to access these molecules efficiently. We have also briefly studied the goldcatalysed intermolecular addition of boronic acids to alkynes. ${ }^{15,20}$ Of particular interest were alkynes containing a suitable 'directing group', which could aid the addition of the boronic acid to the alkyne (Scheme 15). For example, propargylic alcohols $\mathbf{2 0}$ were expected to form boron enolates such as $\mathbf{2 1}$, on treatment with a boronic acid in the presence of a gold catalyst. Instead they were found to undergo a particularly efficient Meyer-Schuster rearrangement to give the corresponding enones 22. ${ }^{20}$ Although we were unable to successfully trap the proposed boron enolate intermediate 21, this reaction provides an extremely mild method for accessing highly substituted enones in good yield, and with moderate to excellent geometrical control.

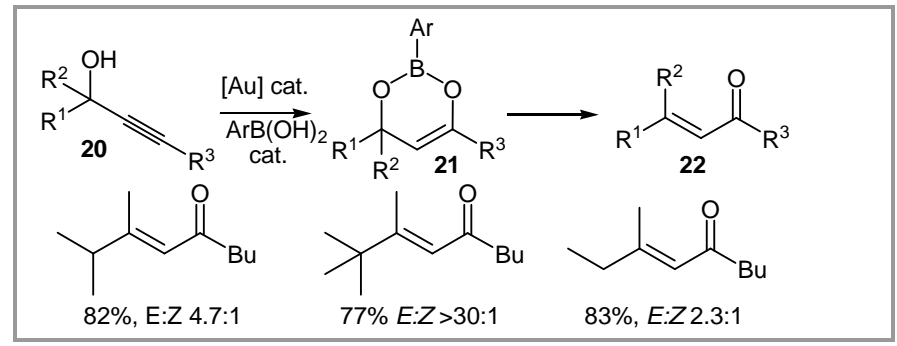

Scheme 15 Gold/boronic acid catalyzed Meyer-Schuster rearrangement.

A number of other strategies for accessing boron and silicon enolates have been reported, but have yet to become widely exploited in synthetic chemistry (Scheme 16). Examples include geminal diboranes $\mathbf{2 3}^{21}$ dihydroxysilanes $\mathbf{2 4},{ }^{22}$ and even simple alkenes $\mathbf{2 5}^{23}$ Such approaches might prove valuable if mild conditions can be found, which are compatible with the presence of electrophiles for the resulting enolate.

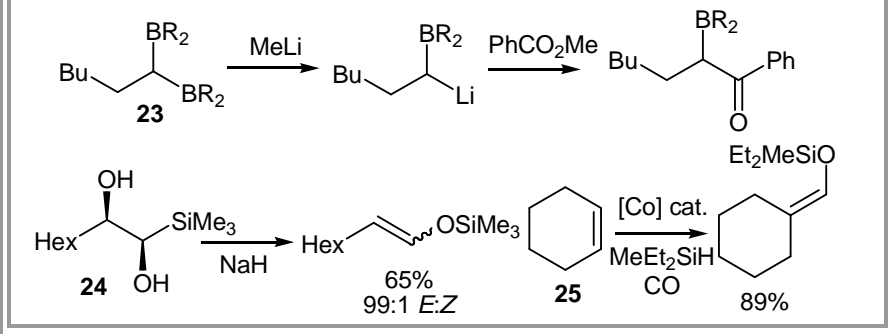

Scheme 16 Miscellaneous methods for enolate generation.

In summary, the generation of enolates from noncarbonyl precursors is becoming a useful strategy for synthetic chemistry. Whilst considerable progress has been made on the generation of enolates from allylic alcohols and, more recently alkynes, there are many potentially fruitful avenues for future research. Both of these strategies are likely to become more widely applicable in the future as ever-improved catalysts are developed, given the ease with which allylic alcohols and alkynes can be prepared. The development of effective catalytic asymmetric protocols is likely to greatly increase the utility of these reactions. The approaches outlined in Scheme 16 are also worthy of further investigation, and the application of simple alkenes as enolate precursors would be extremely useful, given the huge number of readily available alkenes and their low cost.

\section{Acknowledgment}

I would like to thank the EPSRC for supporting my research via the award of an Advanced Research Fellowship (EP/E052789/1).

\section{References}

(1) For representative examples see: (a) Taylor, S. J.; Duffey, M. O.; Morken, J. P. J. Am. Chem. Soc. 2000, 122, 4528; (b) Zhao, C. -X.; Bass, J.; Morken, J. P. Org. Lett. 2001, 3 , 2839; (c) Cauble, D. F.; Gipson, J. D.; Krische, M. J. J. Am. Chem. Soc. 2003, 125, 1110; (d) Agapiou, K.; Cauble, D. F.; Krische, M. J. J. Am. Chem. Soc. 2004, 126, 4528; (e) Deschamp, J.; Chuzel, O.; Hannedouche, J.; Riant, O. Angew. Chem. Int. Ed. 2006, 45, 1292; (f) Welle, A.; Petrignet, J.; Tinant, B.; Wouters, J.; Riant, O. Chem. Eur. J. 2010, 16, 10980.

(2) For relevant reviews see: (a) Notz, W.; Tanaka, F.; Barbas, C. F., III Acc. Chem. Res. 2004, 37, 580; (b) Gaunt, M. J.; Johansson, C. C. C.; MnNally, A.; Vo, N. T. Drug Disc. Today 2007, 12, 8; (c) Pellissier, H. Tetrahedron 2007, 63, 9267; (d) Guillena, G.; Nájera, C.; Ramon, D. J. Tetrahedron Asym. 2007, 18, 2249; (e) Mukherjee, S.; Yang, J. W.; Hoffmann, S.; List, B. Chem. Rev. 2007, 107, 5471; (f) Melchiorre, P.; Marigo, M.; Carlone, A.; Bartoli, G. Angew. Chem. Int. Ed. 2008, 47, 6138; (g) MacMillan, D. W. C. Nature 2008, 455, 304; (h) Bertelsen, S.; Jørgensen, K. A. Chem. Soc. Rev. 2009, 38, 2178.

(3) (a) Edwards, G. L.; Motherwell, W. B.; Powell, D. M.; Sandham, D. A. J. Chem. Soc., Chem. Commun. 1991, 19, 1399; (b) Gazzard, L. J.; Motherwell, W. B.; Sandham, D. A. J. Chem. Soc., Perkin Trans. I 1999, 979.

(4) Motherwell, W. B.; Sandham, D. A. Tetrahedron Lett. 1992, 33, 6187.

(5) (a) Crévisy, C.; Wietrich, M.; Le Boulaire, V.; Uma, R.; Grée, R. Tetrahedron Lett. 2001, 42, 395 (b) Cao, H. T.; Thierry, R.; Grée, R. Lett. Org. Chem. 2009, 6, 507. 
(6) Mac, D. H.; Roisnel, T.; Branchadell, V.; Grée, R. Synlett 2009, 1969.

(7) (a) Cuperly, D.; Petrignet, J.; Crévisy, C.; Grée, R. Chem. Eur. J. 2006, 12, 3261; (b) Petrignet, J.; Roisnel, T.; Grée, R. Tetrahedron Lett. 2006, 47, 7745; (c) Petrignet, J.; Roisnel, T.; Grée, R. Chem. Eur. J. 2007, 13, 7374.

(8) (a) Uma, R.; Davies, M.; Crévisy, C.; Grée, R. Tetrahedron Lett. 2001, 42, 3069; (b) Yang, X. F.; Wang, M.; Varma, R. S.; Li, C. -J. Org. Lett. 2003, 5, 657.

(9) Ahlsten, N.; Martín-Matute, B. Adv. Synth. Catal. 2009, 351, 2657.

(10) Bartoszewicz, A.; Livendahl, M.; Martín-Matute, B. Chem. Eur. J. 2008, 14, 10547.

(11) Basile, T.; Biondi, S.; Boldrini, G. P.; Tagliavini, E.; Trombini, C.; Umani-Ronchi, A. J. Chem. Soc., Perkin Trans. I 1989, 1025.

(12) (a) Boldrini, G. P.; Lodi, L.; Tagliavini, E.; Trombini, C.; Umani-Ronchi, A. J. Organomet. Chem. 1987, 336, 23; (b) Hoffmann, R. W.; Ditrich, K. Tetrahedron Lett. 1984, 25, 1781 .

(13) Murakami, M.; Mukaiyama, T. Chem. Lett. 1982, 241.

(14) Grimster, N. P.; Wilton, D. A. A.; Chan, L. K. M.; Godfrey, C. R. A.; Green, C.; Owen, D. R.; Gaunt, M. J. Tetrahedron 2010, 66, 6429.

(15) Körner, C.; Starkov, P.; Sheppard, T. D. J. Am. Chem. Soc. 2010, 132, 5968.

(16) (a) Arcus, V. L.; Main, L.; Nicholson, B. K. J. Organomet. Chem. 1993, 460, 139; (b) Chen, J.; Bajko, Z.; Kampf, J. W.; Ashe, A. J., III Organometallics 2007, 26, 1563; (c) Greig, L. M.; Kariuki, B. M.; Habershon, S.; Spencer, N.; Johnston, R. L.; Harris, K. D. M.; Philp, D. New J. Chem. 2002, 26, 701; (d) Letsinger, R. L.; Nazy, J. R. J. Am. Chem. Soc. 1959, 81, 3013.

(17) Qiao, J. X.; Lam, P. Y. S. Synthesis 2011, 829.

(18) (a) Shade, R. E.; Hyde, A. M.; Olsen, J. -C.; Merlic, C. A. J. Am. Chem. Soc. 2010, 132, 1202; (b) Quach, T. D.; Batey, R. A. Org. Lett. 2003, 5, 1381.

(19) (a) Huang, H.-Y.; Ishikawa, T.; Peng, C.-F.; Tsai, I.-L.; Chen, I.-S. J. Nat. Prod. 2008, 71, 1146; (b) Pongcharoen, W.; Rukachaisirikul, V.; Phongpaichit, S.; Sakayaroj, J. Chem. Pharm. Bull. 2007, 55, 1404; (c) Jang, J. H.; Kanoh, K.; Adachi, K.; Shizuri, Y. J. Antibiot. 2006, 59, 428.

(20) Pennell, M. N.; Unthank, M. G.; Turner, P.; Sheppard, T. D. J. Org. Chem. 2011, 76, 1479.

(21) Mukaiyama, T.; Murakami, M.; Oriyama, T.; Yamaguchi, M. Chem. Lett. 1981, 1193.

(22) Hudrlik, P. F.; Hudrlik, A. M.; Kulkarni, A. K. J. Am. Chem. Soc. 1985, 107, 4260.

(23) Murai, S.; Sonoda, N. Angew. Chem. Int. Ed. 1979, 18, 837. 


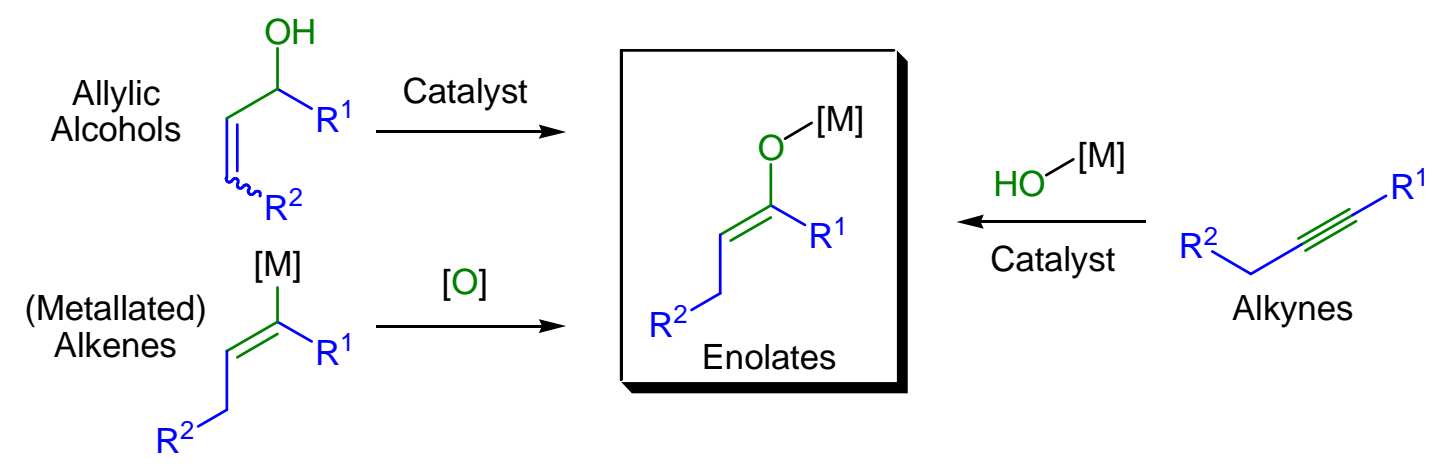

Short Title: Alternative Approaches to Enolates 